\title{
IMPLEMENTASI JARINGAN SYARAF TIRUAN BACKPROPAGATION UNTUK MEMPREDIKSI KETINGGIAN AIR (STUDI KASUS: SUNGAI CILIWUNG)
}

\author{
Rendi Prasetya \\ Program Studi Teknik Informatika, Universitas Indraprasta PGRI \\ Email: prasetyarendi@gmail.com
}

\begin{abstract}
Abstrak
Prediksi ketinggian air selama ini masih dilakukan menggunakan metode statistika. Akan tetapi, akan muncul masalah apabila penelitian dilakukan pada sistem yang dinamis, seperti halnya pada sistem prediksi ketinggian air. Teknologi jaringan syaraf buatan dapat dengan baik mengidentifikasi pola data dari sistem yang dinamis. Penelitian ini dilakukan untuk memprediksi ketinggian air di kota Bogor menggunakan data curah hujan, penguapan dan juga ketinggian air hasil pengamatan pada tahun 2009-2010 perancangan model prediksi menggunakan jaringan syaraf tiruan backpropagation dengan software MATLAB. Karakteristik dari jaringan syaraf tiruan yang digunakan yaitu 1 lapisan masukan dengan 2 neuron (curah hujan dan penguapan), 1 lapisan tersembunyi, dan 1 lapisan keluaran (ketinggian air), nilai laju pembelajaran sebesar 0,9; momentum sebesar 0,1;3 neuron tersembunyi, toleransi galat sebesar 0,0001 dan maksimum epoch sebesar 10000. Dari hasil percobaan yang telah dilakukan dengan perulangan sebanyak 10 kali diperoleh error sebesar $10,93 \%$ dan dapat dikatakan bahwa sistem dapat memprediksi ketinggian air dengan baik.
\end{abstract}

Kata Kunci:jaringan syaraf tiruan, backpropagation, MATLAB

\begin{abstract}
Prediction water level is still done using statistical methods. However, problems will arise if the research done on dynamic systems, as well as the water level prediction system. Artificial neural network technology can properly identify data patterns of a dynamic system. This study was conducted to predict the height of water in Bogor using rainfall data, evaporation and water level, observations in 2009-2010. The design of the prediction model using neural networks backpropagation with MATLAB software. Characteristics of artificial neural networks used are: 1 input layer with two neurons (precipitation and evaporation), one hidden layer and one output layer (water level), the value of the learning rate of 0.9; momentum of 0.1; 3 hidden neurons, error tolerance of 0.0001 and a maximum of 10000 epoch The experimental results by looping earned 10 times the average error was $10.93 \%$, and it can be concluded that the system can properly predict the height of the water.
\end{abstract}

Keyword: artificial neural network, backpropagation, MATLAB

\section{Pendahuluan}

Banjir merupakan suatu salah satu bencana yang menjadi salah satu sorotan bagi Indonesia, khususnya kota Jakarta. Banjir juga salah satu bencana yang berpengaruh paling luas dan menyebabkan kerugian yang tidak kecil (Ma, dkk., 2010). Sejauh ini banjir diakibatkan oleh proses yang berhubungan dengan tinggi permukaan laut dan arus air (Wadey, dkk., 2015). Berangkat dari hal tersebut, maka dibutuhkan solusi yang dapat menyelesaikan masalah tersebut baik dari sisi manusia maupun dalam sisi teknologi.

Objek utama yang digunakan dalam penelitian ini adalah ketinggian air, terutama pada ketinggian air di daerah aliran sungai Ciliwung. Semakin tinggi ketinggian air merupakan salah satu faktor yang dapat menyebabkan potensi terjadinya banjir. Sudah ada beberapa penelitian dalam mengestimasi volume air pada suatu daerah aliran sungai, diantaranya adalah (Youngjoo, dkk, 2012) yang melakukan penelitian mengenai estimasi volume air di salah satu sungai di utara Thailand, kemudian (Zheng, 2012) yang melakukan penelitian 
serupa di sungai Huahei, China dikarenakan kenaikan ketinggian air di sungai ini menyebabkan banjir yang parah sebanyak 3 kali dalam kurun waktu 20 tahun terakhir ini.

Berbagai metode prediksi juga sudah banyak dikembangkan yang sebagian besar menggunakan metode deterministik (kondisi saat $\mathrm{t}$ atau $\mathrm{t}-1$ dan $\mathrm{t}+1$ ) dengan periode harian (Sutikno, dkk., 2013) dimana proses prediksi menggunakan data non-linear. (Indrabayu, dkk, 2012) melakukan penelitian prediksi curah hujan dengan jaringan syaraf tiruan menggunakan Radial Basis Function Neural Network dengan memperhitungkan parameter meteorologi temperatur dan kelembabab, dan juga (Samuel, dkk., 2015) melakukan penelitian serupa dengan memprediksi cuaca di kota bengkulu dengan implementasi jaringan syaraf tiruan backpropagation dengan menggunakan data time series dari suhu, kelembaban dan curah hujan. Oleh karena itu, dalam penelitian ini diusulkan suatu prediksi ketinggian air dengan data curah hujan dan juga penguapan yang menggunakan metode jaringan syaraf tiruan backpropagation. Hal ini peneliti harapkan dapat digunakan untuk memprediksi besarnya ketinggian air secara general tanpa harus terhalang oleh karakteristik dari masing-masing daerah aliran sungai, juga dapat menyajikan data yang real time dengan memprediksi dari data time series yang sebelumnya. Dan juga diharapkan bahwa sistem yang diusulkan ini memiliki tingkat keakuratan yang baik.

Konsep dari sistem yang diusulkan ini yaitu dengan memasukkan data curah hujan, penguapan, dan juga ketinggian air dari periode masa lalu (tahun 2009 - 2010) yang kemudian sistem akan memperhitungkan pola dan juga melakukan proses pelatihan dari pola data yang didapatkan tersebut. Dari proses pelatihan akan dihasilkan bobot-bobot yang nantinya akan digunakan untuk memprediksi besaran ketinggian air pada periode-periode selanjutnya.

\section{Tinjauan Pustaka}

\section{Jaringan Syaraf Tiruan}

Jaringan syaraf tiruan adalah sistem informasi yang memiliki karakteristik yang mirip dengan jaringan syaraf biologi (Siang, 2005a). Jaringan syaraf tiruan adalah jaringan dari sekelompok unit pemroses kecil yang dimodelkan berdasarkan jaringan syaraf manusia (Maria, 2012). Menurut (Siang, 2005b) jaringan syaraf tiruan dibentuk sebagai generalisasi model matematika dari jaringan syaraf biologi dengan asumsi sebagai berikut:

a. Pemrosesan informasi terjadi pada banyak elemen sederhana (neurons)

b. Sinyal dikirimkan diantara neuron-neuron melalui penghubung-penghubung

c. Penghubung antar neuron memiliki bobot yang akan memperkuat atau memperlemah sinyal

d. Untuk menentukan keluaran (output), setiap neuron menggunakan fungsi aktivasi (biasanya bukan fungsi linier) yang dikenakan pada penjumlahan masukan (input) yang diterima.

Neuron adalah unit pemroses informasi yang menjadi dasar dalam pengoperasian jaringan syaraf tiruan (Siang, 2005c). Neuron terdiri dari 3 elemen pembentuk sebagai berikut:

a. Himpunan unit-unit yang dihubungkan dengan jalur koneksi

b. Suatu unit penjumlah yang akan menjumlahkan masukan-masukan sinyal yang sudah dikalikan dengan bobotnya.

Fungsi aktivasi yang akan menentukan apakah sinyal dari input neuron akan diterukan ke neuron lain ataukah tidak.

\section{Arsitektur Jaringan Syaraf Tiruan}

Berdasarkan arsitekturnya, model jaringan syaraf tiruan digolongkan menjadi:

a. Jaringan Layar Tunggal (Single Layer Network) 
Pada jaringan ini, sekumpulan masukan neuron dihubungkan langsung dengan sekumpulan keluarannya. Sinyal mengalir searah dari layar (lapisan) masukan sampai lapisan keluaran.

Setiap simpul dihubungkan dengan simpul lainnya yang berada diatasnya dan dibawahnya, tetapi tidak dengan simpul yang berada pada lapisan yang sama. Model yang masuk kategori ini antara lain: ADALINE, Hopfield, Perceptron, LVQ. Pada Gambar 1 diperlihatkan arsitektur jaringan layar tunggal dengan $\mathrm{n}$ buah masukan $\left(x_{1}, x_{2}, \ldots, x_{n}\right)$ dan $m$ buah keluaran $\left(y_{1}, y_{2}, \ldots, y_{m}\right)$

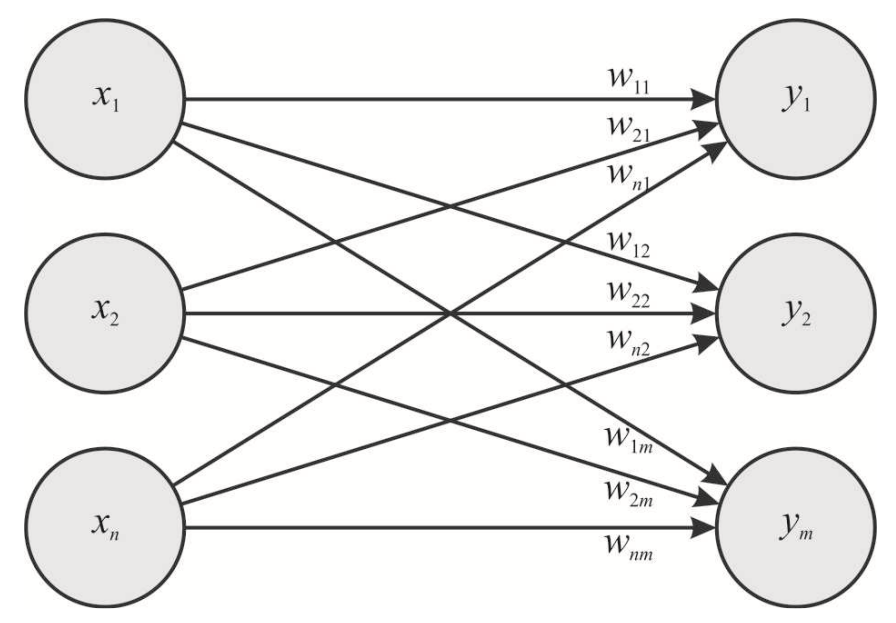

Gambar 1. Jaringan Layar Tunggal

b. Jaringan Layar Jamak (Multiple Layer Network)

Jaringan ini merupakan perluasan dari jaringan layar tunggal. Dalam jaringan ini, selain unit masukan dan keluaran, ada unit-unit lain (sering disebut lapisan tersembunyi). Dimungkinkan pula ada beberapa lapisan tersembunyi. Model yang termasuk kategori ini antara lain: MADALINE, backpropagation.

Pada Gambar 2 diperlihatkan jaringan dengan $\mathrm{n}$ buah unit masukan $\left(x_{1}, x_{2}, \ldots, x_{n}\right)$, sebuah lapisan tersembunyi yang terdiri dari $\mathrm{m}$ buah unit $\left(z_{1}, z_{2}, \ldots, z_{p}\right)$ dan 1 buah unit keluaran.

c. Jaringan Reccurrent

Model jaringan recurrent (reccurrent network) mirip dengan jaringan tungal ataupun jamak. Hanya saja, ada simpul keluaran yang memberikan sinyal pada unit masukan (sering disebut feedback loop). Dengan kata lain sinyal mengalir dua arah, yaitu maju dan mundur. Contoh: Hopfield Network, Jordan Network, Elmal Network. 


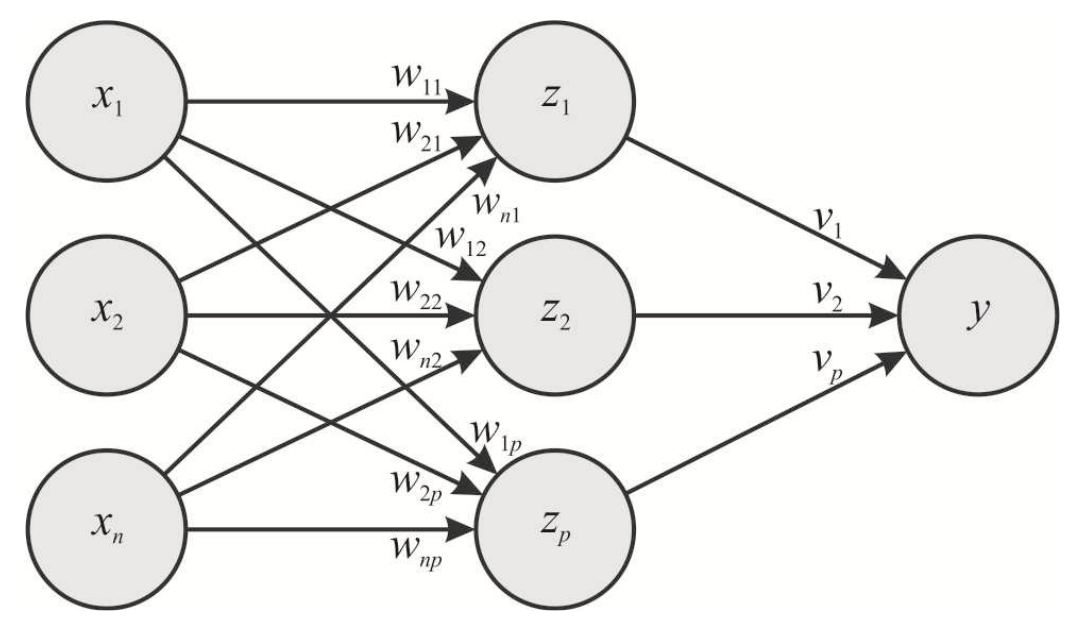

Gambar 2. Jaringan Layar Jamak

\section{Jaringan Syaraf Tiruan Backprogation}

Secara umum proses jaringan syaraf tiruan terbagi menjadi 2 bagian yaitu training dan testing. Struktur algoritma backpropagation secara lengkap adalah:

a. Langkah 1 Inisialiasi

Tentukan angka pembelajaran $(\alpha)$. Tentukan pula nilai toleransi error yang diinginkan dan set maksimal epoch (iterasi) jika ingin membatasi epoch yang digunakan. Inisialisasi bobot dan bias sesuai dengan bobot yang dihasilkan pada proses pelatihan.

b. Langkah 2

Setiap input $\left(x_{i}, i=1,2, \ldots, n\right)$ menerima sinyal input dan menyebarkan sinyal input pada seluruh lapisan tersembunyi.

c. Langkah 3

Setiap lapisan tersembunyi $\left(z_{j}, j=1,2, \ldots, p\right)$ akan menghitung sinyal-sinyal input dengan bobot dan biasnya.

$$
z i n_{j}=v_{0 j}+\sum_{i=1}^{n} x_{i} v_{i j}
$$

fungsi aktivasi untuk menghitung sinyal outputnya, yaitu:

$$
z_{j}=v_{0 j}+\sum_{i=1}^{n} x_{i} v_{i j}
$$

kemudian dengan menggunakan fungsi aktivasi yang telah ditentukan diperoleh sinyal output dari lapisan tersembunyi tersebut dan mengirimkan sinyal tersebut ke semua unit lapisan di atasnya (lapisan keluaran).

d. Langkah 4

Setiap unit output $\left(y_{k}, k=1,2, \ldots, m\right)$ akan menjumlahkan sinyal-sinyal dari lapisan tersembunyi dengan bobot dan biasnya.

fungsi aktivasi untuk menghitung sinyal outputnya, yaitu:

$$
\begin{gathered}
y i n_{k}=w_{0 k}+\sum_{j=1}^{p} z_{j} w_{j k} \\
y_{k}=w_{0 k}+\sum_{j=1}^{p} z_{j} w_{j k}
\end{gathered}
$$

kemudian dengan menggunakan fungsi aktivasi yang telah ditentukan diperoleh sinyal output dari unit output tersebut.

$$
y_{k}=f\left(y i n_{k}\right)
$$


e. Langkah 5

Setiap unit outputy ${ }_{k}$ menerima pola target $t_{k}$ untuk menghitung error $\left(\delta_{k}\right)$, yaitu:

$$
\delta_{k}=\left(t_{k}-y_{k}\right) f^{\prime}\left(y n e t_{k}\right)=\left(t_{k}-y_{k}\right) y_{k}\left(1-y_{k}\right)
$$

kemudian hitung nilai koreksi bobot yang nantinya digunakan untuk memperbaiki nilai bobot antara lapisan tersembunyi dan lapisan output $\left(w_{j k}\right)$, yaitu:

$$
\delta w_{j k}=\alpha \delta_{k} z_{j}
$$

hitung juga koreksi bias yang digunakan untuk memperbaiki nilai bias antara lapisan tersembunyi dan lapisan output $\left(w_{o k}\right)$, yaitu

$$
\delta w_{0 k}=\alpha \delta_{k}
$$

f. Langkah 6

Setiap unit pada lapisan tersembunyi menjumlahkan sinyal-sinyal input dari lapisan output, yaitu:

$$
\delta i n_{j}=\sum_{k=1}^{m} \delta_{k} w_{j k}
$$

kalikan nilai ini dengan fungsi aktivasi untuk menghitung error pada lapisan tersembunyi $\left(\delta_{j}\right)$, yaitu:

$$
\delta_{j}=\delta i n_{j} f^{\prime}\left(z i n_{j}\right)=\delta i n_{j} z_{j}\left(1-z_{j}\right)
$$

kemudian hitung koreksi bias untuk memperbaiki nilai bobot antara lapisan input dan lapisan tersembunyi $\left(v_{i j}\right)$, yaitu:

$$
\delta v_{i j}=\alpha \delta_{j} x_{i}
$$

kemudian hitung koreksi bias untuk memperbaiki nilai bobot antara lapisan input dan lapisan tersembunyi $\left(v_{0 j}\right)$, yaitu:

$$
\delta v_{0 j}=\alpha \delta_{j}
$$

g. Langkah 7

Tiap-tiap unit keluaran memperbaiki bobot dan bias, yaitu:

$$
w_{j k}(\text { baru })=w_{j k}(\operatorname{lama})+\delta w_{j k} ; k=1,2, \ldots, m ; j=0,1, \ldots, p
$$

tiap-tiap unit tersembunyi memperbaiki bobot dan bias, yaitu:

$$
v_{i j}(\text { baru })=v_{i j}(\operatorname{lama})+\delta v_{i j} ; j=1,2, \ldots, m ; i=0,1, \ldots, n
$$

h. Langkah 8

Tes kondisi berhenti. Selama kondisi berhenti tidak terpenuhi, lakukan langkah ke2 sampai ke-8.

Notasi yang digunakan dalam algoritma pengujian:

$x_{i}=$ unit input ke-i

$v_{i j}=$ bobot antara unit input ke-i dengan hidden unit ke-j

$z_{j} \quad=$ hidden unit ke-j

$w_{0 k}=$ bias untuk unit output ke-k

$y_{k}=$ unit output ke-k

$w_{j k}=$ bobot antara hidden unit ke-j dengan unit output ke-k

$t_{k} \quad=$ pola target ke-k

$\delta_{k}=$ error

$v_{0 j}=$ bias untuk hidden unit ke-j

Untuk lebih mengerti tentang algoritma backpropagation, dapat kita perhatikan arsitektur jaringannya pada Gambar 3 di bawah ini. 


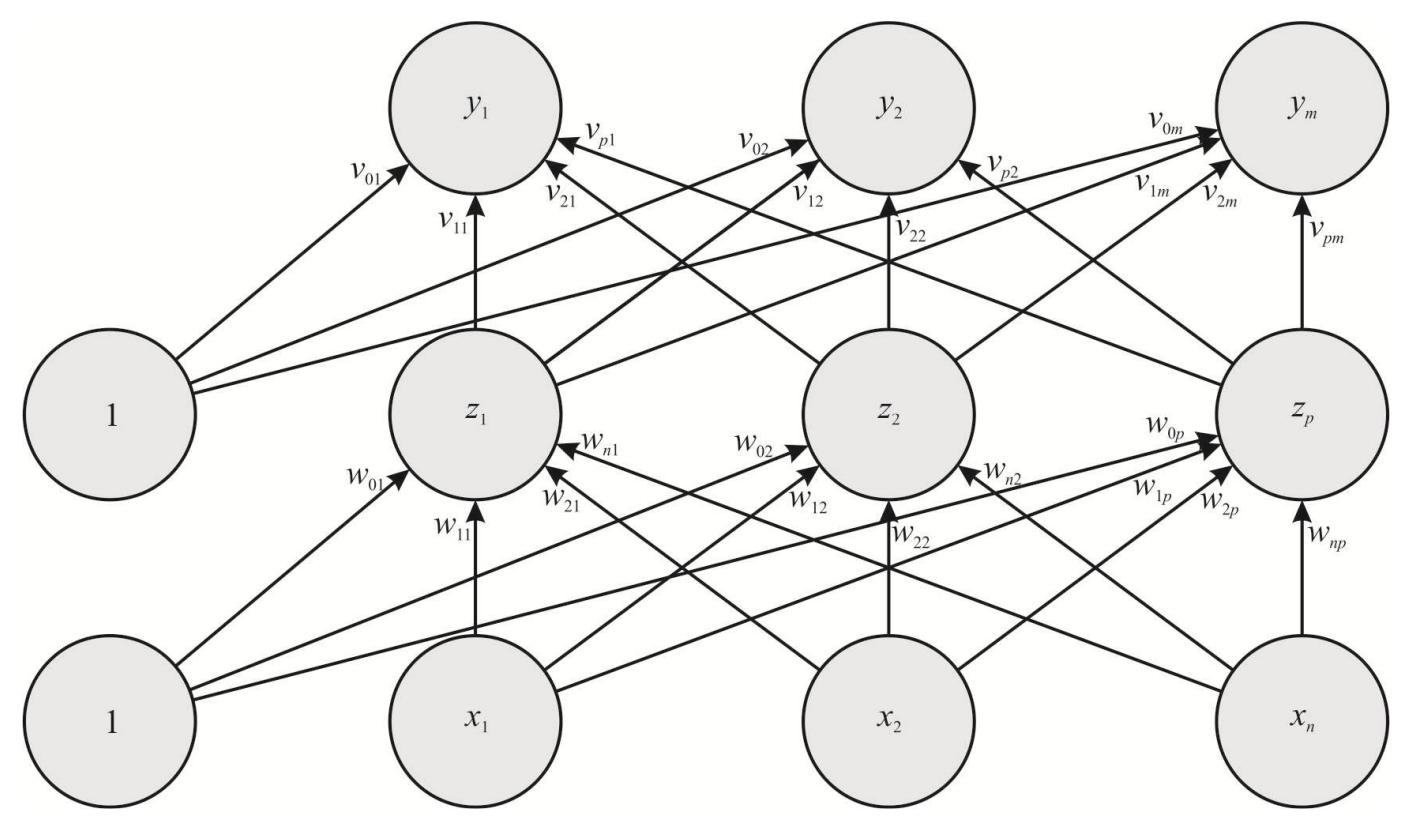

Gambar 3. Arsitektur Jaringan Backpropagation

\section{Backpropagation dalam Peramalan}

Salah satu bidang dimana backpropagation dapat diaplikasikan dengan baik adalah bidang prediksi (peramalan). Peramalan yang sering kita dengan adalah peramalan besarnya penjualan, nilai tukar valuta asing, dll. Sebagai contoh, dalam penjualan barang, diketahui record data penjualan suatu produk beberapa bulan/tahun terakhir. Masalahnya adalah memperkirakan berapaperkiraan produk yang terjual dalam bulan/tahun yang akan datang.

Secara umum, masalah peramalandapat dinyatakan sebagai berikut: Diketahui sejumlah data runtun waktu (time series) $x_{1} . x_{2}, \ldots, x_{n}$. Masalahnya adalah memperkirakan berapa harga $x_{n+1}$ berdasarkan $x_{1} . x_{2}, \ldots, x_{n}$. Dengan backpropagation, record data dipakai sebagai data pelatihan untuk mencari bobot yang optimal. Untuk itu kita perlu menetapkan besarnya periode dimana data berfluktuasi. Periode ini kita tentukan secara intuitif. Misalkan pada data besarnya ketinggian air sungai dengan data bulanan, periode data dapat diambil selama satu tahun karena pergantian musim terjadi selama satu tahun.

Jumlah data dalam satu periode ini dipakai sebagai jumlah masukan dalam backpropagation. Sebagai targetnya diambil data bulan pertama setelah periode berakhir. Pada data bulanan dengan periode satu tahun, maka masukan backpropagation yang dipakai terdiri dari 12 masukan. Keluaran adalah 1 unit. Bagian tersulit adalah menentukan jumlah lapisan (dan unitnya). Tidak ada teori yang dengan pasti dapat dipakai. Tapi secara praktis dicoba jaringan yang kecil terlebih dahulu (misal terdiri dari 1 lapisan tersembunyi dengan beberapa unit saja). Jika gagal (kesalahan tidak turun dalam epoch yang besar), maka jaringan diperbesar dengan menambahkan unit tersembunyi atau bahkan menambah lapisan tersembunyi.

\section{Metodologi Penelitian}

Langkah-langkah yang dilakukan dalam membangun struktur jaringan syaraf tiruan untuk memprediksi ketinggian air di suatu daerah aliran sungai adalah sebagai berikut:

1. Pengumpulan data

Pengumpulan data dilakukan secara sekunder. Pengumpulan data yang digunakan mencakup data curah hujan, data penguapan dan juga data ketinggian air.Pengumpulan data curah hujan dan penguapan diambil dari Badan Meteorologi, Klimatologi dan Geofisika Stasiun Klimatologi Darmaga, Bogor. Data curah hujan merupakan akumulasi 
data harian dari 8 kali pencatatan perharinya, pencatatan dilakukan setiap 3 jam sekali dengan satuannya adalah $\mathrm{mm}$. Data penguapan merupakan data harian dari satu kali pencatatan setiap harinya dengan satuannya adalah $\mathrm{mm}$. Semua data diambil pada jam 7 WIB (00.00 GMT), dengan data yang didapat hari ini merupakan data hari sebelumnya.Pengumpulan data ketinggian didapatkan dari Balai Pendayagunaan Sumber Daya Air Wilayah Sungai Ciliwung - Cisadane, Bogor. Data ketinggian air diambil dari rataan 3 kali pengambilan data (pagi, siang dan sore) setiap hari di Bendungan Katulampa, Bogor dengan satuannya adalah $\mathrm{cm}$.Periode pengambilan data berselang dari awal bulan September 2009 sampai dengan akhir bulan September 2010. Jumlah data yang digunakan dalam karya ilmiah ini sebanyak 395 data.

2. Transformasi data

Data ditransformasi agar kestabilan tebaran data dicapai. Selain itu berguna untuk menyesuaikan nilai data dengan kisaran fungsi aktivasi yang digunakan dalam jaringan (Siang, 2005d).Persamaan yang digunakan untuk transformasi data dalam karya ilmiah ini yaitu:

$$
y=\lim _{a \rightarrow 0^{+}, b \rightarrow 1^{-}}(b-a) \frac{x-x_{\min }}{x_{\max }-x_{\min }}+a
$$

dengan,

$y \quad=$ nilai data setelah ditransformasi

$x \quad=$ nilai data aktual

$a \quad=$ nilai minimum data transformasi yang diinginkan

$b=$ nilai maksimum data transformasi yang diinginkan

$x_{\min }=$ nilai minimum data aktual keseluruhan

$x_{\max }=$ nilai maksimum data aktual keseluruhan

Untuk data curah hujan, penguapan, dan ketinggian air pada karya ilmiah ini ditransformasikan ke dalam kisaran nilai 0,001 sampai dengan 0,098.

3. Pembagian data

Data dibagi menjadi data pelatihan, pengujian dan validasi. Komposisi data pelatihan, pengujian dan validasi yang digunakan pada penelitian ini adalah sebagai berikut:80\% untuk data pelatihan dan $20 \%$ untuk data pengujian dan validasi.Aspek pembagian data ini harus ditekankan agar jaringan syaraf tiruan yang kita gunakan mendapat data pelatihan yang cukup dan data pengujian yang dapat menguji kinerja pelatihan yang dilakukan. Bilangan data yang kurang untuk proses pelatihan akan menyebabkan jaringan mungkin tidak dapat mempelajari pola data dengan baik. Sebaliknya, data yang terlalu banyak untuk proses pelatihan akan melambatkan proses pemusatan. Masalah overtraining (data pelatihan yang berlebihan) akan menyebabkan jaringan cenderung untuk menghafal data yang dimasukan daripada menggeneralisasi.

4. Perancangan struktur jaringan yang optimum

Dalam penelitian ini digunakan 1 lapisan masukan dengan 2 neuron (curah hujan dan penguapan), 1 lapisan tersembunyi dan juga 1 lapisan keluaran dengan 1 neuron (ketinggian air). Dalam openelitian ini digunakan hanya 1 lapisan tersembunyi, hal ini dikarenakan arsitektur jaringan yang digunakan masih sederhana. Penentuan bilangan neuron pada lapisan tersembunyi yang terbaik diperoleh secara trial and error dari simpul 1 sampai $2 \mathrm{n}$ dengan $\mathrm{n}$ adalah jumlah neuron pada lapisan masukan. Karena dalam karya ilmiah ini hanya terdapat 2 neuron pada lapisan masukan maka bilangan neuron pada lapisan tersembunyi berkisar dari 1 sampai dengan 4 neuron.

5. Memilih dan menggunakan struktur jaringan yang optimum Jaringan yang dibangun akan dinilai keakuratannya. Metode penilaian yang digunakan adalah nilai Mean Absolute Percentage Error (MAPE) dan Mean Square Error (MSE). 
Pendekatan MAPE dan MSE digunakan untuk menilai kinerja jaringan yang dilatih. Nilai MAPE danMSE diperoleh dari persamaan di bawah ini :

dengan,

$$
M A P E=\sum_{1}^{n} \frac{|P E|}{n}
$$

$n=$ banyaknya data yang diprediksi

$|P E|=$ nilai mutlak dari $\mathrm{PE}$

dengan,

$$
M S E=\frac{1}{n} \sum_{i=1}^{n}\left(y_{i}-\widehat{y}_{l}\right)
$$

$n=$ banyaknya data yang diprediksi

$y_{i}=$ nilai aktual data ke-i

$\widehat{y}_{l}=$ nilai prediksi data ke-i

Keakuratan dari jaringan syaraf tiruan ini dilihat dari nilai MAPE dan MSE pada proses pengujian dan validasi. Semakin kecil nilai MAPE dan MSE maka jaringan syaraf tiruan pun akan semakin akurat untuk melakukan proses prediksi atau pendugaan terhadap parameter yang kita inginkan.

\section{Hasil dan Pembahasan}

Pada penelitian ini, digunakan komposisi pembagian data $80 \%$ untuk data pelatihan dan $20 \%$ untuk data pengujian, dengan karakteristik dari jaringan syaraf tiruan yang digunakan yaitu 1 lapisan masukan dengan 2 neuron (curah hujan dan penguapan), 1 lapisan tersembunyi, dan 1 lapisan keluaran (ketinggian air), nilai laju pembelajaran sebesar 0,9; momentum sebesar 0,$1 ; 3$ neuron tersembunyi, toleransi galat sebesar 0,0001 dan maksimum epoch sebesar 10000 .

Tabel 1. Error Hasil Pengujian Jaringan Syaraf Tiruan

\begin{tabular}{cccc}
\hline Percobaan ke- & Error yang dihasilkan & Percobaan ke- & Error yang dihasilkan \\
\hline I & 11.00385 & VI & 10.86861 \\
II & 11.25161 & VII & 10.70206 \\
III & 10.51953 & VIII & 10.82181 \\
IV & 11.07973 & IX & 10.98943 \\
V & 11.16680 & X & 10.86051 \\
\hline
\end{tabular}

Dari hasil pengujian dengan 10 kali pengulangan diperoleh rataan error sebesar 10,93\% sehingga dapat dikatakan bahwa jaringan syaraf tiruan dapat memprediksi besaran ketinggian air dengan baik. Dengan grafik hasil pengujian dapat dilihat pada Gambar 5 . Untuk nilai kesalahan dalam setiap perulangan percobaan pun dapat dikatakan seragam. Terlihat pada Tabel 1 yang memperlihatkan nilai error pada setiap proses perulangan percobaan. 


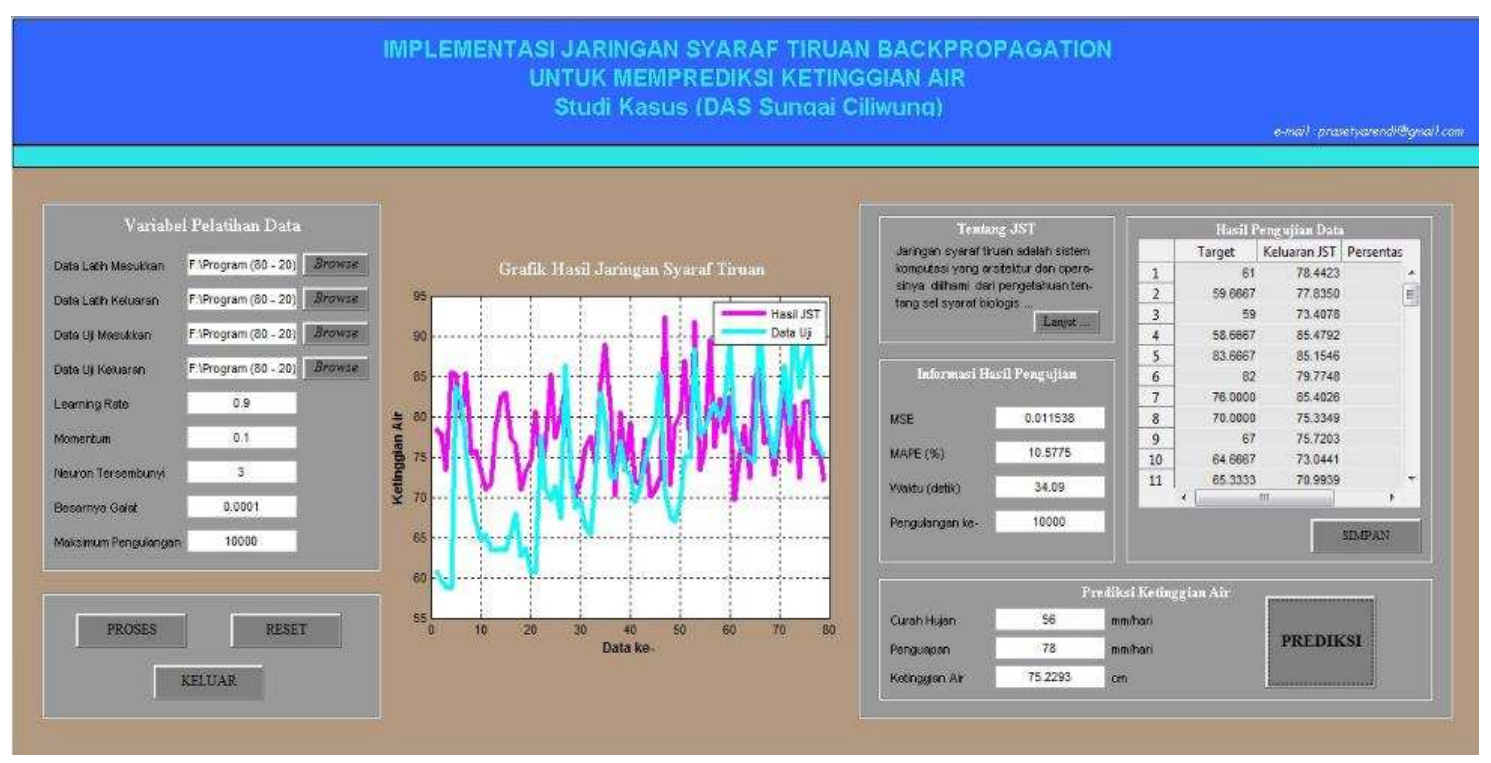

\section{Gambar 4. Tampilan Aplikasi Jaringan Syaraf Tiruan dengan Matlab}

Maka dapat disimpulkan bahwa jaringan syaraf tiruan dengan algoritma backpropagationpada penelitian ini dapat digunakan untuk memprediksi besaran ketinggian air di suatu daerah aliran sungai, terlihat dari nilai error yang kecil sebesar 10,93\% dengan perulangan error yang dapat dikatakan seragam.

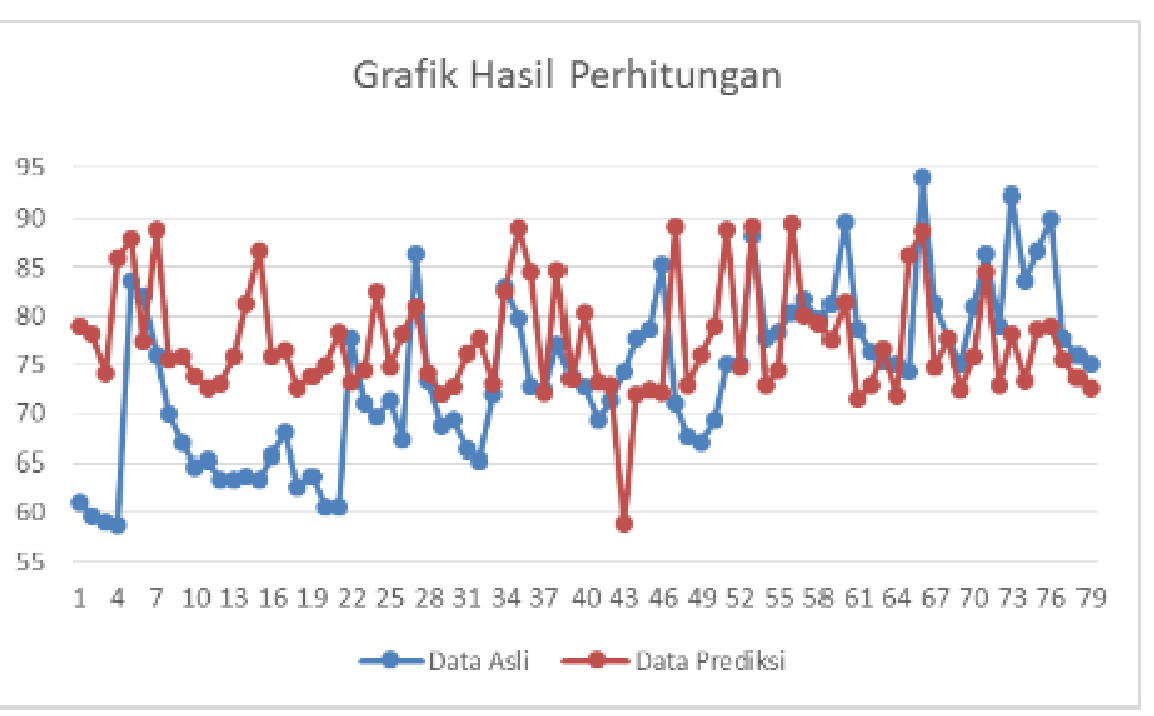

\section{Gambar 5. Grafik Perbandingan Data Asli dengan Data Hasil Prediksi}

\section{Simpulan dan Saran}

Berdasarkan dari penelitian yang telah dilakukan dapat ditarik kesimpulan bahwa jaringan syaraf tiruan backpropagation dengan karakteristik 1 lapisan masukan dengan 2 neuron, 1 lapisan tersembunyi dan 1 lapisan keluaran dengan 1 neuron dapat digunakan untuk memprediksi ketinggian air di suatu daerah aliran sungai dengan baik. Hal ini terlihat dari nilai error yang diperoleh sebesar $10,93 \%$.

Akan tetapi masih diperlukan penelitian lebih mendalam dengan variasi algoritma pelatihan yang digunakan. Transformasi data lain juga perlu dilakukan agar tebaran dari data lebih 
stabil. Metode optimasi data seperti Swarm Optimization, Wavelet Neural, Genethic Algorithm dapat juga diterapkan agar tingkat keakuratan lebih tinggi.

\section{Daftar Pustaka}

Haryanto, S.A.F., Ernawati, Diyah, P. (2015). Implementasi Jaringan Syaraf Tiruan Backpropagation untuk Memprediksi Cuaca (Studi Kasus: Kota Bengkulu). Jurnal Rekursif, Vol. 3 No.2, November 2015. ISSN: 2303-0755

Indrabayu, Nadjamuddin, H., M., Saleh Pallu, Andani A., Fikha, C.L., (2012). Prediksi Curah Hujan dengan Jaringan Syaraf Tiruan. Prosiding Teknik Elektro Fakultas Teknik Universitas Hasanudin. Vol. 6, Desember 2012. ISBN: 978-979-127255-0-6

Ma, D., Ding, N., Wang, J., Cui, J. (2010).Research on Flood Submergence AnalysisSystem Based on ArcEngine Component Library. Ministry of Construction P.R.ChinaScience \& Technology Planning Project (2010-K9-24).

Maria, A. (2012). Penggunaan Jaringan Syaraf Tiruan Backpropagation untuk Seleksi Penerimaan Mahasiswa Baru Pada Jurusan Teknik Komputer di Politeknik Negeri Sriwijaya. Program Pascasarjana, Magister Sistem Informasi, Universitas Diponegoro: Semarang

Siang, J.J. (2005). Jaringan Syaraf Tiruan dan Pemrogramannya Menggunakan MATLAB. Yogyakarta: ANDI

Sutikno, Bekti, R., Susanti, P., Istriana. (2010). Prakiraan Cuaca Dengan Metode Autoregressive Integrated Moving Average, Neural Network, dan Adaptive Splines Threshold Autoregression di Stasiun Juanda Surabaya. Jurnal SAINS Dirgantara.

Wadey, M.P., Cope, S.N., Nicholls, R.J., McHugh, K. (2015). Coastal Flood Analysis and Visualisation for A SmallTown. Ocean \& Coastal Management 116(2015) 237e247

Youngjoo, K., Jonggeol, P., Atsuhiro. Y., Kazuhiko. F. (2012). Estimation Of Flood Volume in Chao Phraya River Basin,Thailand, From Modis Images Couppledwith Flood Inundation Level. InternationalCentre for Water Hazard and Risk Management (ICHARM) under the auspicesof UNESCO, Public Works ResearchInstitute (PWRI), 978-1-4673-1159-5/12/\$31.00 @2012 IEEE.

Zheng, W. (2012). The Flood Monitoring Information System Framework Based onMultisource Satellite Remote Sensing Data. International Conference on System Science and Engineering June 30 - July 2,2012, Dalian, China. 